\title{
Train-the-Trainers Biology Workshop as an Effective Science Advocacy Tool: An Impact Assessment and Emerging Issues for Science Education
}

\author{
Izuchukwu Azuka Okafor ${ }^{1,2}$, Smart Ikechukwu Mbagwu',3, Chinyere Elizabeth Eze ${ }^{1}$, Jennifer Chizoba Oluwatayo4, \\ Obinna Nonso Anachuna ${ }^{5}$, and Chris Okwuchukwu Obialor ${ }^{6}$ \\ ${ }^{1}$ Department of Anatomy, College of Health Sciences, ${ }^{4}$ Department of Early Childhood and Primary Education, ${ }^{5}$ Department of Educational Management and Policy, \\ and ${ }^{6}$ Department of Science Education, Nnamdi Azikiwe University, Nnewi, Nigeria; ${ }^{2}$ Department of Obstetrics and Gynecology, Pan African University of Life and \\ Earth Science Institute (Including Health and Agriculture) PAULESI, University of Ibadan, Ibadan, Nigeria; and ${ }^{3}$ Anatomy Section, Department of Oncology, Microbiol- \\ ogy and Immunology, University of Fribourg, Fribourg, Switzerland \\ Keywords: Science Advocacy, Biology Workshop, Science Education Outreach, Impact Assessment, Teacher Training, Train-the-Trainer Workshop, Professional \\ Development
}

Publication Date: February 22, 2021

DOI: https://doi.org/10.15695/jstem/v4i1.02

\begin{abstract}
Science advocacy is a vital tool for ensuring improved and more beneficial science education, especially in resource-poor countries. This study assessed the impact of a train-the-trainer biology workshop (TTTBW) as a useful instrument for science advocacy and maximizing biology teacher training. Thirty-one biology teachers $(30 \%$ male and $70 \%$ female) competitively selected from 25 secondary schools in urban areas of Anambra State Nigeria participated in the two-day TTTBW. They were taught several pre-identified and need-based topics as part of professional development. Some of the topics taught include A) Effective communication skills for biology teaching; B) Teaching management skills; C) Dynamics of child education; D) New pedagogical skills in teaching Biology; E) Strategies for targeted Assessment in Biology; and F) Adaptation of Biology teaching for resource-poor countries. Each topic lasted for at least an hour, and a pre and post-test was done for topics A-C and analyzed. Pre-workshop assessment and post-workshop impact assessment interviews were also carried out through an online form and self-administered questionnaire, respectively. There was a significant increase in the teachers' post-test scores in topics examined (A-C) compared to the pre-test scores ( $\mathrm{p}=0.00,0.00$, and 0.004 respectively). After the workshop, the interest in teaching biology increased in most of the participants (91\%) compared to $23 \%$ before the workshop. TTTBW is a potent tool for science advocacy and professional development for teachers and exhibits scale-up potentials for maximal impact.
\end{abstract}

\section{INTRODUCTION}

Science is a yardstick by which development is measured globally, and a key to technological growth which plays an essential role in improving human lives. The development of any nation is measured by the degree and extent to which socio-cultural, socio-economic and political developments are achieved through the enterprise of science (Olorundare, 2011).

Despite the revolutionary changes seen in science over the years, the teaching of science in Nigeria still lacks adequate innovation and reform in its pedagogy (Avalos, 1995; Omorogbe and Ewansiha, 2013). There is a growing increase in the level of school dropout from sciences in recent years in the world (United Nation, 2013) as studies have shown that the likelihood of dropping out of school is higher for science students than arts (Nakkazi, 2014; Woodhouse, 2015; Brown, 2017). Nigeria has the highest number of school dropouts in the world (United Nation, 2013). It brings the need to build science teachers who can raise new thinkers

and scientists of the 21 st century and make studying science more fun and student-friendly in Nigeria to the forefront (Odia and Omofonmwan, 2007; Florence, 2015; Wilson et al., 2016). A recent study has identified the inefficiencies in most schools' pedagogical approach in teaching and learning science in Nigeria (Udu, 2018) which poses a significant threat to students' enrollment in science and science advocacy success in Nigeria. Science subjects are generally seen as 'difficult' and need a more proactive, practical, innovative, and pragmatic pedagogy in teaching and learning especially at the primary and secondary school levels, to "catch them young' (Aina, 2013).

Buseri (2010) opines that to meet up with the rapid scientific and technological advancements requires the presence of well-trained, efficient, knowledgeable, and skilful teachers who are versatile in discharging their duties and responsibilities, as no educational system can rise above the quality of its teachers. A proper and regular training and re-training 
of science teachers are sacrosanct in achieving maximum impact through science education. Through experience and scholarship, some thematic areas of need have been identified in the past as essential areas to consider during science teachers' professional development (Odia and Omofonmwan, 2007; Florence, 2015; Udu, 2018). Some of these were considered during the inaugural train-the-trainers biology workshop (TTTBW) organized for teachers in Anambra state, Nigeria. Some of the topics covered include a) effective communication skills for biology teaching; b) teaching management skills c) dynamics of child education; d) new pedagogical skills in teaching biology; e) strategies for targeted assessment in biology; and f) adaptation of biology teaching for resource-poor countries.

The passion for contributing our quota to salvage science education in Nigeria through motivation and professional development of teachers brought about the design of the TTTBW. The words of Plato, "do not then train youths to learning by force and harshness, but direct them to it by what amuses their minds so that you may be better able to discover with accuracy the peculiar bent of the genius of each" summarizes the objectives of this program (Goodreads, n.d.). TTTBW was geared towards exposing biology teachers to critical and transferable effective teaching and learning skills in biology, using professional seminars, interactive lectures, one-on-one learning, knowledge assessment sessions, teaching, practical simulations, and group discussions. The main aim of the workshop was to train teachers who will continually train other teachers within their schools, to be able to have a sustainable impact on the students. All the training materials (CDs containing the recorded version of all workshop lectures and biology simulation videos) were given to each trained teacher to reproduce and further train other biology teachers in their school. These materials were given to enable each teacher to refresh on the course and also to be able to have a useful reference when transferring the knowledge gained. The participants were also given an eye model and a dissecting set as biology instructional material for their schools. The participants of TTTBW have been well informed and had consented to their future role of training other teachers and schoolchildren after the workshop with the training and instructional materials provided for them. The envisaged long-term impact of this program will be monitored and evaluated through a systematic follow-up strategy.

Over time, teachers' training and retraining have been seen as a veritable tool for the sustenance of educational growth and impact (Florence, 2015). However, this has been neglected in Nigeria, mainly due to inadequate funding and a lack of educational leadership (Odia and Omofonmwan, 2007; Nwafor et al., 2015). This article reports an apparent attempt to initiate and evaluate the impact of a train-thetrainer workshop model for biology teachers as a veritable tool for science advocacy.

Journal of STEM Outreach

\section{METHODS}

Study Type and Setting. This questionnaire-based descriptive impact assessment study was carried out in the train-thetrainers biology workshop (TTTBW) held between 7th and 8th January 2020 at Anatomy Department, Nnamdi Azikiwe University, Nnewi Campus, Nigeria.

Recruitment of Teachers for TTTBW. The TTTBW participants were recruited through an online form at www.formsite.com through the link - https://fs22.formsite. com/FRPjY0/wemfvuyzoe/index.html?1576622997975 between and December 1-25, 2019. A Bachelor's degree in biology or biology education is the standard qualification for being a biology teacher at the secondary school level in Nigeria. However, TTTBW recruitment was not restricted to this standard. The program was not targeted at teachers at any specific experience level but included biology teachers whose professional needs would be met. The selection criteria were based on the following:

- Being a secondary school biology teacher

- Availability to attend and participate fully in the workshop

- Knowledge-transfer ability

- The motivation for the workshop

- Potential for impact

The criteria mentioned above were assessed through an online participant recruitment forms filled by the teachers before the workshop. The form had questions that assessed all the above-stated criteria. However, knowledge-transfer ability, motivation for the workshop, and potential for impact were assessed subjectively, but were scored and independently assessed by the TTTBW coordinators. The teachers who had the highest average scores were selected to participate in the workshop. Out of fifty-three teachers that applied, thirty-two teachers $(\sim 60 \%)$ with varying teaching experience levels $(<2$ to $>5$ years) were selected, with regards to the funding capacity for the workshop; however, only thirty-one participants fully attended the workshop ( 97\%).

Train-The-Trainers Biology Workshop. The workshop covered need-based thematic areas with the objective of science advocacy and improved biology teachers' knowledge, teaching skills, class management skills, and overall teacher effectiveness. Each topic was taught for at least an hour and was handled by experts in biology, education, psychology, science communication, and management. Some of the topics taught and their objectives are summarized below:

Effective Communication Skills for Teaching Biology. At the end of this topic the teachers should be able to:

- Apply communication strategies in their daily teaching tasks 
- Use specific communication styles to increase students' understanding of science

- Use specific communication styles to increase students' interest in science

Teaching Management Skills (Time and Class Size Management). At the end of this topic the teachers should be able to:

- Apply management skills to their daily teaching tasks

- Manage their class size to make an effective output

- Manage their teaching periods to meet teaching and curriculum targets

- Manage teaching resources for maximum output

- Manage students for more productivity

Dynamics of Child Education. At the end of this topic the teachers should be able to:

- Apply different skills needed to teach an adolescent effectively.

- Identify what could constitute child abuse in adolescent education

- Identify peculiarities that make an adolescent and how to manage them as a teacher

New Pedagogical Skills in Teaching Biology Teaching. At the end of this topic the teachers should be able to:

- Utilize effective pedagogical (teaching) planning

- Apply the pedagogical competencies and approaches (the 4Cs - collaboration, communication, creativity, and critical thinking) in teaching

- Apply specific biological teaching methods

- Apply teaching instruction and effective student interaction

Strategies for Targeted Assessment in Biology. At the end of this topic the teachers should be able to:

- Outline the importance of assessment

- Identify different types of assessments used in the sciences

- Create an effective assessment

- Design assessment for specific purposes in biology

Adaptation of Biology Teaching for Poor-Resource Countries. At the end of this topic the teachers should be able to:

- Identify educational infrastructural challenges in resource-poor countries

- Apply coping mechanisms and adaptation strategies to sustain effective teaching

- Apply innovations in teaching biology

Other workshop activities included:

- Biology practical simulations

- Breakout sessions for discussions of topical issues in education

- Anatomy museum tour
Workshop Impact Assessment. All the participants of TTTBW participated in the impact assessment evaluation. This assessment's objective was to determine the immediate impact of TTTBW on the participants and the overall perception of participants about the program. A de-identified questionnaire was designed and peer-reviewed with quantitative and qualitative assessment components for the overall assessment of the workshop's impact. The questionnaire had a mix of open-ended, closed, or Likert-scale (1-5) question types. A preliminary pilot testing was done with a small target audience, and modifications were made to the questionnaire following the outcome. The final questionnaire draft was tested for consistency using internal consistency (Cronbach's alpha of 0.7), test-retest reliability, and inter-rater reliability (Kappa statistic, $\mathrm{K}=0.9$ ) before final validation by science education and teacher training experts. The questionnaire was self-administered by all the participants at the end of the last day (day 2) of the workshop. It contained a section on personal information (age, sex, level of education) and an impact assessment section (see results section). Pre and post-test were also administered ten minutes before and one week after each of the topics were taught. However, by convenient sampling and following the topics the teachers had indicated more interest in during the recruitment process, pre and post-tests were only carried out for topics A to $\mathrm{C}$ and analyzed for statistical differences. Trained workshop volunteers graded these tests with answers provided by the course facilitators.

Statistics Analysis. All data (online recruitment and post-workshop impact assessment) were de-identified, cleaned of errors, coded, and entered into excel before transfer for analysis using IBM SPSS version 21. The qualitative data were screened to generate common themes which were reviewed by two authors independently before inclusion. The quantitative data were analyzed using the descriptive statistics while the pre and post-test scores were analyzed using the student t-test. All data collected were used for the analysis. Data were considered significant at $\mathrm{p}<0.05$.

\section{RESULTS}

TTTBW Participant Characteristics. There are thirty-one TTTBW participants (70\% female; 30\% male) recruited from twenty-five different secondary schools with private schools contributing the highest number $(51 \%)$ of teachers trained (Table 1). Public and missionary schools made up the rest of the participants (Table 1). The largest and median age group of participants is $26-35$ years, representing $52 \%$ of the total participants, while $7 \%$ were between $18-25$ years (Table 2).

Most of the participants $(73 \%, \mathrm{n}=23)$ have a bachelors degree with a few $(10 \%, n=3)$ having a secondary school 
Table 1. TTTBW Participants' School Distribution. Data are presented in the nearest whole numbers and percentages.

\begin{tabular}{lll}
\hline School type & $\begin{array}{l}\text { Number of schools } \\
(\mathbf{N})(\%)\end{array}$ & $\begin{array}{l}\text { Number of persons } \\
(\mathbf{N})(\%)\end{array}$ \\
\hline Missionary School & $3(12)$ & $3(10)$ \\
Private school & $11(44)$ & $16(51)$ \\
Public schools & $11(44)$ & $12(39)$ \\
Total & $\mathbf{2 5 ( 1 0 0 )}$ & $\mathbf{3 1}(\mathbf{1 0 0})$ \\
\hline
\end{tabular}

certificate or its equivalent as their highest qualification (Figure 2). These qualifications were more in the biology-related speciality (for example agriculture, science education, chemistry, anatomy, microbiology) $(54 \%, n=17)$ than in biology or biology education specifically $(43 \%, n=13)$ (Figure 2). $26 \%$ (8) of the participants teach biology and biology-related subjects; $63 \%$ (20) of the participants teach non-biolo-

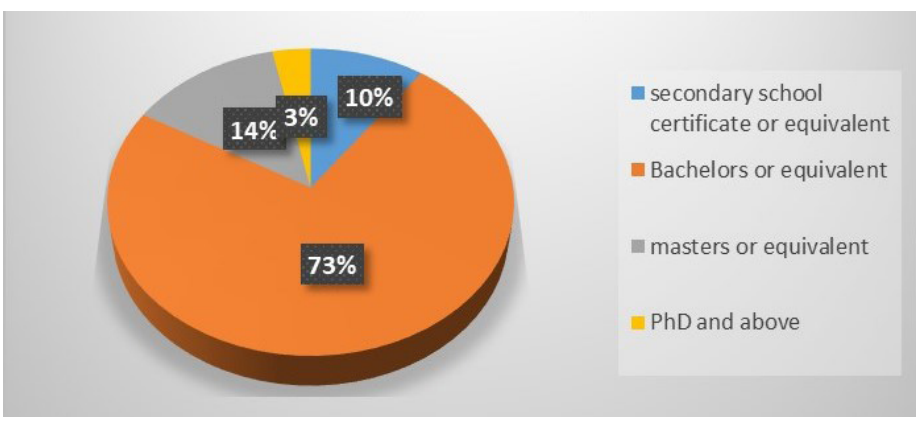

Figure 1. Level of Education of TTTBW Participants. The values are given in the nearest whole number. The total number of teachers interviewed $=31$.

gy related science subjects while $11 \%$ (3) teach non-science subjects (Figure 3). A significant number $(62 \%)$ of the participants teach one extra subject other than biology while just a few (15\%) teach only biology (Figure 4). The participants have a median class size of 50-100 students, with $10 \%$ having a class size of $<25$ students (Table 3 ). The participants' highest and median teaching experience was $>5$ years, while $17 \%$ had $<2$ years of teaching experience (Table 4 ).

TTTBW Pre-workshop Interview. The workshop topic preferences were assessed before the workshop with most participants $(72 \%, \mathrm{n}=22)$ showing interest in the topic 'new pedagogical skills in teaching biology'. In comparison, be-

Table 2. Age Distribution of TTBW Participants. Data are presented in the nearest whole numbers and percentages.

\begin{tabular}{ll}
\hline Age groups (years) & Frequency $(\mathbf{N}) \mathbf{( \% )}$ \\
\hline$<18$ & $0(0)$ \\
$18-25$ & $7(22)$ \\
$26-35$ & $16(52)$ \\
$>35$ & $8(26)$ \\
Total & $\mathbf{3 1}(\mathbf{1 0 0})$ \\
\hline
\end{tabular}

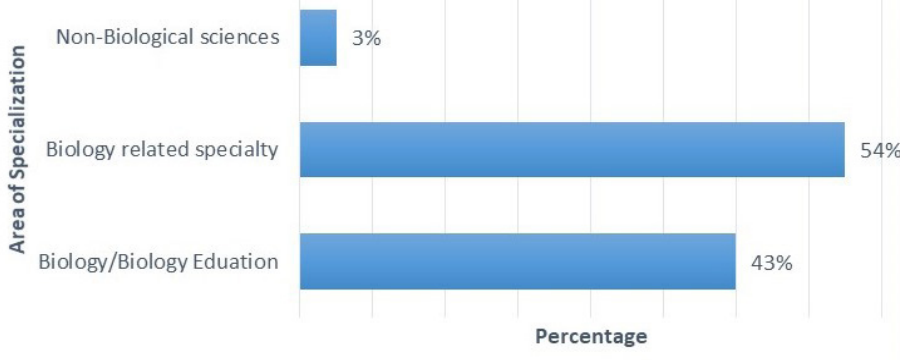

Figure 2. Area of Specialization of TTTBW Participants. The values are given in the nearest whole number. The total number of teachers interviewed $=31$. The area of specialization shows the degree title that qualifies the teacher as a biology teacher. Biology related speciality includes all science courses except biology or biology education. Non-biological sciences include all non-science courses

tween $3-6 \%$ were interested in other topics (Figure 5). Also, $77 \%$ (24) of the participants revealed that they would likely not be a biology teacher in the next five years (Table 5). However, the participants expressed enthusiasm in the transfer of knowledge that will be gained in the workshop through different means such as 1) classroom teaching 2) organizing school mini-workshops 3) personal interaction with students and colleagues 4) departmental board meetings 5) group discussions 6) material sharing. One of the participant's response reads: "I intend to transfer the knowledge gained in this workshop through the following ways: 1. One-on-one interaction with my colleagues and interested individuals 2. By organizing mini-workshops in primary, secondary, and tertiary institutions 3. By printing and publishing works which are based on the knowledge acquired from the workshop."

\section{TTTBW Overall Satisfaction and Impact Assessment.}

Our questionnaire-based impact assessment was focused on identifying the participants' level of satisfaction with the most critical aspects of the TTTBW. All the participants $(100 \%)$ either agree or strongly agree that the facilitators knew the subject matter well while $95 \%$ agree or strongly agree that they gave clear explanations to the topics covered (Figure 6). No participant disagreed or strongly disagreed

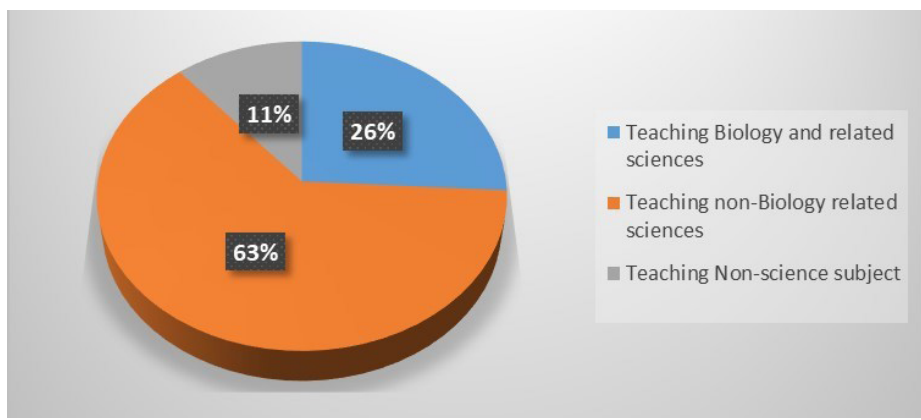

Figure 3. Subject Areas taught by TTTBW Participants. The values are given in the nearest whole number. The total number of teachers interviewed $=31$. 
Table 3. Class Size of TTTBW Participants. Data are presented in the nearest whole numbers and percentages.

\begin{tabular}{ll}
\hline Class size & Frequency $(\mathbf{N}) \mathbf{( \% )}$ \\
\hline$<25$ students & $3(10)$ \\
$25-50$ students & $10(35)$ \\
$50-100$ students & $7(24)$ \\
$>100$ students & $9(31)$ \\
Total & $\mathbf{2 9}(\mathbf{1 0 0})$ \\
\hline
\end{tabular}

that the lecture speed was appropriate or that the facilitators appropriately answered their questions (Figure 6). Figure 6 also showed that only $22 \%$ of the participants agreed that the speed of the lectures was appropriate, while more than half $(56 \%)$ agree or strongly agreed that the facilitators welcomed or responded well to questions. The majority of the participants $(74 \%, \mathrm{n}=23)$ agreed or strongly agreed that the topics taught in the workshop were relevant though only about one-third (31\%) agreed or strongly agreed that the topics were new to them (Figure 6). Most of the participants (91\%) agreed or strongly agreed that the workshop increased their interest in teaching biology, while others $(9 \%, n=3)$ were indifferent (Figure 6). 96\% of the participants agreed or strongly agreed that they would recommend the workshop to other biology teachers and all the participants scored the TTTBW above average (26\%) or excellent $(74 \%)$ (data are not shown).

\section{Responses to the Post-Workshop Evaluation Interview.} What part of the workshop interested you more and why? The participants expressed general satisfaction with all the aspects of the workshop but were particular about some of the workshop aspects which included the lectures (new pedagogical skills, effective communication skills for teaching biology, teaching management skills), biology practical simulations, and the teachers' breakout sessions. Some of the teachers' responses read:

Teacher 1: "The lectures taught me some new skills and sharpened those I already know. The breakout periods helped me to understand co-teachers experiences...It gave me insights on the new methods of teaching science subjects as a whole".

Table 4. Teaching Experience of TTTBW Participants. Data are presented in the nearest whole numbers and percentages.

\begin{tabular}{ll}
\hline Teaching experience (years) & Frequency (N) (\%) \\
\hline$<2$ & $5(17)$ \\
$2-5$ & $8(28)$ \\
$>5$ & $16(55)$ \\
Total & $\mathbf{2 9 ( 1 0 0 )}$ \\
\hline
\end{tabular}

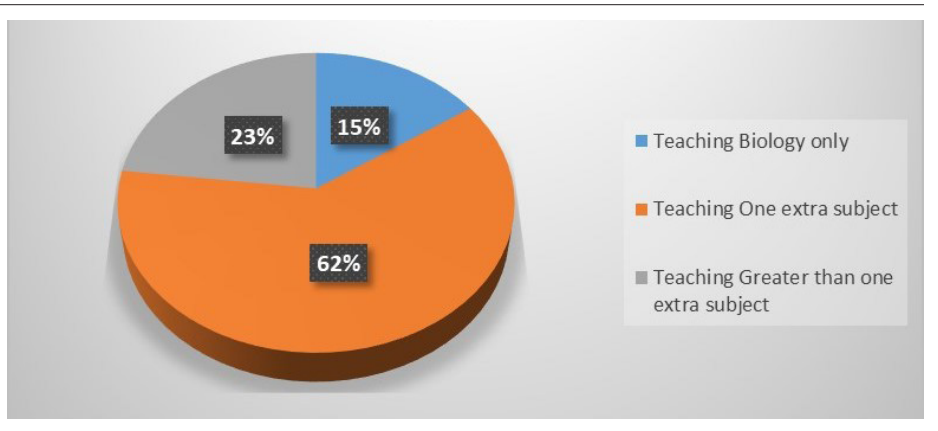

Figure 4. Number of Subjects Taught by TTTBW Participants. The values are given in the nearest whole number. The total number of teachers interviewed $=31$.

Teacher 2: "Communication is the main medium for transferring knowledge. So I was much interested in it and as such I learnt the various skills to use while handling the students especially the verbal communication skills".

Teacher 3: "I actually want to say that almost all the aspects of the workshop interests me..."

What topics or issues were not clear to you? The participants ascertained the clarity of the topics discussed in the workshop:

Teacher 1: "how to combine teaching and copying note..."

Teacher 2: "All the topics were all clear and all the resource persons were good - the explanations were all good and well taken."

Teacher 3: "how we can improvise for biology teaching due to lack of funds"

What topics would you like to be taught in the future workshop? The teachers suggested several topics as possible topics for future workshops. A teacher noted this to include 'different concepts in biology that are difficult to teach' with examples given as genetics and evolution, Kreb's cycle, new classification principles, cellular respiration, glycolysis, etc. Many teachers mentioned that information and communication technology (ICT) useful in biology teaching and learning should be considered for future workshops. A teacher said: "To expose teachers to modern facilities such

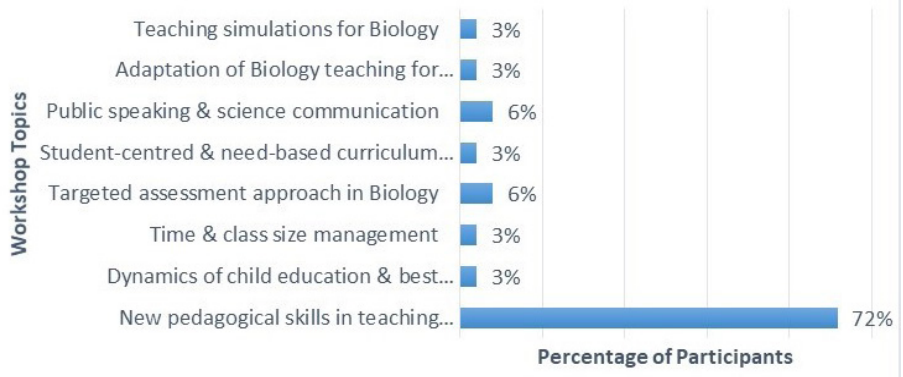

Figure 5. TTTBW Participants Pre-Workshop Topic Preferences. The values are given in the nearest whole number. The total number of teachers interviewed $=31$. 
Table 5. TTTBW Participants' Likelihood of Remaining a Biology Teacher. Data are presented in the nearest whole numbers and percentages.

\begin{tabular}{ll}
\hline $\begin{array}{l}\text { Will you still be a biology teach- } \\
\text { er in the next } 5 \text { years? }\end{array}$ & Frequency $(\mathbf{N})(\%)$ \\
\hline Yes & $7(23)$ \\
No & $24(77)$ \\
Total & $\mathbf{3 1}(\mathbf{1 0 0})$ \\
\hline
\end{tabular}

as the use of projections, laptops, computer, internet, etc". Other new areas to learn in the future noted by the teachers include biology practical other than simulations, guidance and counselling skills, innovative mindset for teachers, how to curb exam malpractice and how to make an effective scheme of work for biology.

Pre and Post Subject Evaluation. The analysis of pre and post-test scores (A-C) in topics covered in TTTBW showed significantly higher scores $(p<0.05)$ in the post-test scores of participants compared to the pre-test scores in topics covered in the workshop, with the participants having the highest mean post-test scores in topic A (effective communication skills for teaching Biology) (Table 6).

TTTBW Participants' Recommendations. Several recommendations were made by the teachers and are summarized as follows:

- More teachers should be invited to future workshops.

- More practical work should be done.

- The workshop should be extended to other parts of the country.

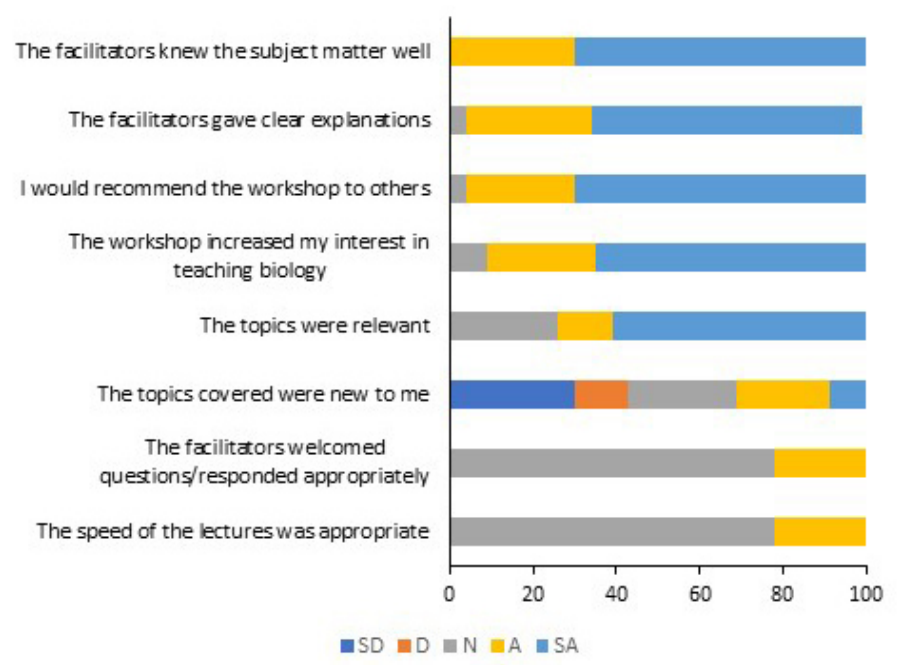

Figure 6. TTTBW Overall Satisfaction and Impact Assessment. Likert scale (1-5) was used for this assessment: $1=$ strongly disagree (SD), 2 = disagree (D), $3=$ neutral $(\mathrm{N}), 4=\operatorname{agree}(\mathrm{A})$, $5=$ strongly agree (SA). Questions with zero responses were not shown in the bar charts; thus, those not shown have $0 \%$. The values are given in the nearest whole number. The total number of teachers interviewed $=31$.
Table 6. Pre and Post-Test Scores of Participants in A-C Topics Covered in TTTBW. Data are presented as mean score \pm standard deviation (SD). ${ }^{*}$ represents statistical significance at $p<0.05$ following a student $t$-test for the pre-test and post-test of topics $A-C$.

\begin{tabular}{llll}
\hline Test & Mean scores \pm SD & $p$-value & $\boldsymbol{t}$-value \\
\hline Pre-test Score A & $7.45 \pm 1.74$ & $0.000^{*}$ & -4.517 \\
Post-test Score A & $9.05 \pm 1.13$ & & \\
Pre-test Score B & $5.04 \pm 1.55$ & $0.000^{*}$ & -5.984 \\
Post-test Score B & $7.33 \pm 1.58$ & & \\
Pre-test Score C & $6.95 \pm .83$ & $0.004^{*}$ & -3.249 \\
Post-test Score C & $7.95 \pm 1.23$ & & \\
\hline
\end{tabular}

- Free materials for biology practical should be given to the participants for implementation.

- Accommodation should be provided for teachers in future workshops.

- The workshop should be done at least annually.

Some of the comments read:

Teacher 1: "...I think this kind of workshop should be organized often or maybe annually to improve teaching."

Teacher 2: "Biology practical involving the participants either learning from a facilitator or among themselves in groups"

\section{DISCUSSION}

Teacher training and motivation have long been used as a tool for ensuring stability, productivity, and effectiveness in teaching and learning (Ofojebe and Ezugoh, 2010). There are variations of professional needs across different levels of teaching, school type, and personal expertise (OECD, 2009). TTTBW was carried out with the mindset of reaching out to a mixed teacher population with common professional needs. Our study involved a fair share of male to female ratio (1:2) (data not shown) with a median age of 26-35 years (Table 2) spread across different types of schools (Table 1) and with varying educational qualifications (Figure 1) and levels of experience (Table 4). This is typical of Adedokun (2016) report in his demographic study of secondary school teachers in Nigeria.

Several problems have been identified as being peculiar to science education in Nigeria (Avalos, 1995; Odia and Omofonmwan, 2007; Adedokun, 2016; National Academies of Sciences [NAS], 2016). Our study cohorts' baseline characteristics showed proof of some of these earlier documented challenges and some emerging ones. We observed that about $10 \%$ of the teachers assessed in this study teach biology but have no minimum qualification to teach biology at the secondary school level (Figure 1). Among those that have a university degree, our study revealed that their degree specialization was more in biology-related courses than biology 
or biology education itself with even a few teachers having a non-biological science-related degree (Figure 2). Our findings are supported by the earlier publications that reported the massive employment of unqualified youths as teachers in Nigerian schools (Aina, 2016). This has been found to adversely affect the students' performance (Akinsolu, 2010). More than half of the teachers who participated in TTTBW teach one extra subject asides from biology with more than $70 \%$ of these number teaching either a non-biology related subject or a non-science subject within the same school (Figure 3-4). Amidst having unqualified teachers teach multiple subjects, the teachers are also faced with another difficulty - large class size. Our study cohort has a median class size of 50-100 students per teacher (Table 3). It will lead to inefficiency and reduce the level of the impact made on the students due to ineffective class management (Ngoboka, 2002; Jepsen, 2015).

The problems of science education in a resource-poor country like Nigeria could be multifaceted (Avalos, 1995; Odia and Omofonmwan, 2007; NAS, 2016), which has been substantiated by this present study to include unqualified science teachers, non-specialization of teachers, and large class sizes. Our study could not explain why unqualified teachers are being engaged in teaching biology even in urbanized areas where most of the teachers recruited for this study work (data not shown). We could infer that there could be a declining interest in teaching biology at the secondary school level or a shortage of qualified biology teachers in Nigeria as already opined by some studies (Adeyemi, 2011; Lawali et al., 2015). This is following the significant number of participants $(77 \%)$ who were unwilling to remain a biology teacher in the next five years (Table 5). The unwillingness to remain a biology teacher could also result from low job satisfaction by the teachers (Mukuni, 2013). The large class sizes were suggested to be due to the lack of infrastructure, inadequate funding, or a mere desire to cut personnel cost (Ngoboka, 2002; Jepsen, 2015).

Following a pre-workshop teacher assessment, we observed a remarkable lack of new pedagogical skills needed for biology teaching. Most of the TTTBW participants indicated an interest in learning this skill compared to other topics taught at TTTBW (Figure 5). This exposes that the teachers lacked the much needed continuing professional development (CPD) (Avalos, 1995; NAS, 2016). Also, about one-third of the teachers interviewed agreed that the topics they were taught were entirely new to them (Figure $6)$. This is corroborated by the $78 \%$ of teachers who were unsure whether the speed of the lectures they had during the workshop was appropriate for them (Figure 6).

One of the most important indicators of the effectiveness of TTTBW as a tool for science advocacy is the reversal of the lack of interest to teach biology which the teachers earlier expressed before the workshop (Table 5). The post-work- shop impact evaluation report showed that most participants $(91 \%)$ agreed or strongly agreed that the workshop increased their interest in teaching biology. Hurd (1962) had long argued that what gives a biology teacher a good look is their education level and interest in teaching biology. Hence, increasing the interest in teaching biology should be paramount in the training of biology teachers; however, it is not clear whether this increased interest would influence their decision to remain a biology teacher for years to come. This can only be determined through a follow-up or longitudinal study. All the participants also attested that TTTBW was either above average or excellent (data are not shown) based on its overall activities. This is clear evidence that TTTBW could be a veritable tool for science advocacy, howbeit, with a clearly defined need-based objective.

The test scores of the TTTBW participants were observed to be significantly higher than the pre-test scores in all the three different topics (A-C) examined (Table 6). This is further proof of the level of impact TTTBW could make in specific teacher education themes. It could be noted that the teachers performed better in topic A - 'effective communication skills for biology' (post-test score A) compared to other topics (B and C) (Table 6). This is not surprising as most of the teachers highlighted during the interview that the lecture is one of their high points during the workshop. One of the teachers said, "communication is the main medium for transferring knowledge. So I was much interested in it and as such I learnt the various skills to use while handling the students especially the verbal communication skills". This level of the impact made by TTTBW on the teachers could be attributed to the fact that the facilitators know their subjects well, gave clear explanations to the topics taught, and answered the teachers' questions appropriately (Figure 6). These findings have revealed the need for a more sustainable TTTBW prototype to be developed which could be in the mainstream of the teachers' CPD or the training of newly employed science teachers as should be necessitated (Zulkifli, 2014).

The teachers have identified several areas where more training would be needed in the future. These include, according to one of the teachers: "different concepts in biology that are difficult to teach", use of ICT in teaching, practical other than simulations, guidance and counselling skills, how to curb examination malpractice, developing an effective scheme of work, and how to be innovative as a science teacher. The role of ICT in effective teaching and learning has been described (Aina, 2013); thus ICT skills should be prioritized in teacher's training as the demand for these skills by workshop participants shows that this is lacking or inadequate. A study by Oyeronke and Fagbohun (2013) reported a lack of these skills in their study cohort.

The overall impact made by TTTBW regardless of the baseline characteristics, year of experience, and lev- 
el of expertise of the teachers showed its effectiveness and adaptability as a tool for science advocacy, especially in resource-poor countries. However, there may be a need to consider other environmental and socio-cultural factors (Olmos-Gómez et al., 2019) which may affect the effectiveness of TTTBW when being adapted or implemented in any other locality atypical to our study setting.

The key performance indicators of TTTBW includes not just the ability and willingness to transfer the knowledge garnered from the workshop but also the effectiveness of such transfer when made. There are known teaching methods that facilitate more effective knowledge transfer from the teacher to other teachers and students (Lakatos and Borsos, 2011; Van Doorn and Van Doorn, 2014). There is a need to have a measurable follow-up strategy for any workshop such as TTTBW when being executed to ensure and monitor its effectiveness. Some useful follow-up strategies for teacher training and professional development have been earlier recommended by O'Sullivan (2002). In this present study, the participants showed enthusiasm and willingness to transfer the knowledge gained after the workshop. This is one of the major criteria also considered during the selection of TTTBW participants. They were also detailed in how they would transfer the knowledge gained in TTTBW to other colleagues. One of the teacher's response reads: "I intend to transfer the knowledge gained in this workshop through the following ways: 1 . One-on-one interaction with my colleagues and interested individuals 2 . By organizing mini workshops in primary, secondary and tertiary institutions 3. By printing and publishing works which are based on the knowledge acquired from the workshop." This could be a sign of possible success with the knowledge transfer in their different schools (Van Doorn and Van Doorn, 2014), given that all the lecture materials used for the workshop were made available to all TTTBW participants.

Nevertheless, it could be argued that the capability of knowledge transfer may differ amongst teachers. A teacher hinted during the interview that he/she can still not understand how to cope with teaching and copying notes on the blackboard (as required by most schools in resource-poor countries), even after the workshop. However, all TTTBW participants ascertained the clarity of the topics taught during the workshop. This tells that the efficacy of the teachers' transfer of knowledge will be mostly dependent on the level of understanding of the topics taught during the workshop (Van Doorn and Van Doorn, 2014). This current study does not provide any evidence on the efficacy or effectiveness of the transfer of knowledge gained during the TTTBW it described, as the participants are still under follow-up for this purpose.

The teachers have made some useful recommendations regarding TTTBW, which borders on increasing the number of participants, participant funding, regularity, and program scope. This draws attention to the much-needed funding for teacher education and training especially in resource-poor countries (Nwafor et al., 2015) and calls for a more synergistic effort by governments, charities, institutions, professional bodies, scientific societies, and philanthropists towards science advocacy and teacher training.

Limitations. TTTBW is a pilot program that has shown many prospects for impact but has room for significant improvement. We have reported and discussed results based on a small sample of 31 biology teachers, even though they are recruited across 25 different schools. This may limit all possible interpretations and elucidations that the larger teacher cohort may offer. However, we do not claim our interpretations to be exhaustive, which was not our study's aim. Our findings highlight that even with a small sample, there was a considerable change in knowledge before and after TTTBW. It also suggested the need to scale up such training as an effort towards teacher professional development or in-service training, especially in areas with a shortage of qualified science teachers. The selection of recruited participants was also based on those who have agreed through the recruitment application to transfer the knowledge gained in the workshop and be assessed for the same. Hence some teachers who may have benefited more from the program could have been left out. The high variability of the teaching experience and educational level of the teachers who participated in the workshop may have affected the workshop's observed impact. There may be a need for an extensive evaluation of the impact of TTTBW across the varying levels of education and teaching experience. The teachers were only assessed in topics A-C taught in the workshop following the teachers' interests alone, thus limiting the study purview. Again, we have developed the TTTBW based on our perceptions and personal communication between teachers in our locality on biology teachers' needs. Hence, there may be a need for a comprehensive assessment of teachers' professional needs which could be considered as a scale-up plan for TTTBW, for maximum impact. We could not provide all the necessary teaching aid support for the participants to sufficiently transfer the knowledge gained in this workshop to other teachers and students due to limited funding. Impact of TTTBW may be limited when any of the schools could not provide these teaching aids.

\section{CONCLUSION}

The result of this study reveals significant findings on the impact of TTTBW on teachers. First, the data shows a significant increase in the teachers' knowledge base on several important biology workshop topics and their interest in teaching biology. These findings are fascinating considering the 'mixed quality' of the teachers. It also brings to fore the 
necessary things to prioritize when planning or executing a training program for teachers. Our findings have vital implications for science teacher professional training.

\section{AUTHOR INFORMATION Corresponding Author}

Izuchukwu Azuka Okafor. Department of Anatomy, Faculty of Basic Medical Sciences, College of Health Sciences, Nnamdi Azikiwe University, Nnewi Campus. PMB 5001, Nnewi, Nigeria.

\section{Author Contributions}

IAO and SIM designed the study concept and protocol. All the authors executed the project and IAO did the data analysis. The first draft was done by IAO while all the authors reviewed and approved the final draft of the manuscript.

\section{ACKNOWLEDGMENTS}

We are grateful to the American Association for Anatomy (AAA) for sponsoring TTTBW through the science outreach grant awarded to IAO. We also thank Prof. Ukoha Ukoha, the head of the Anatomy department at Nnamdi Azikiwe University for agreeing to host the TTTBW; and also the facilitators and volunteers who participated in TTTBW.

Conflict of Interest. The authors have no conflict of interest to declare.

Ethical Considerations. The organizers did not have access to any institutional review board before the program but followed all the ethical guidelines for questionnaire and survey-based study as approved by the National Health Research Ethics Committee of Nigeria (NHREC). Also, the study followed due compliance with the Helsinki Declaration. All the program participants gave full consent for their data to be used for research purposes.

Data Availability Statement. The data used for this study will be provided upon written request to the corresponding author.

\section{ABBREVIATIONS}

CPD: Continuing Professional Development; ICT: Information and Communication Technology; NAS: National Academies of Sciences; NHREC: National Health Research Ethics Committee of Nigeria; TTTBW: Train-the-Trainer Biology Workshop

\section{REFERENCES}

Adedokun, A. A. (2016). Nigeria secondary school teachers , demographics, perception, and level of technology integration: A correlational study [Doctoral dissertation, Keiser University]. Academia. https://www.academia. edu/41444098/nigeria_secondary_school_teachers_demographics_perception_and_level_of_technology_integration_a_correlational_study

Adeyemi, T. (2011). Teacher shortages and surpluses in senior secondary schools in Ondo State, Nigeria: A critical review. American Journal of Social and Management Sciences, 2(3), 304-315. https://doi.org/10.5251/ ajsms.2011.2.3.304.315

Aina, J. K. (2013). Effective teaching and learning in science education through information and communication technology [ICT]. IOSR Journal of Research and Method in Education, 2(5), 43-47.

Aina, J. K. (2016). Employment of untrained graduate teachers in schools: The Nigeria case. Journal of Studies in Social Sciences and Humanities, 2(2), 34-44.

Akinsolu, A. O. (2010). Teachers and students' academic performance in Nigerian secondary schools: Implications for planning. Florida Journal of Educational Administration and Policy, 3(2), 86-103.

Avalos, B. (1995). The development of human resources: the provision of science education in secondary schools. Issues in Science Teacher Education. UNESCO: International Institute for Educational Planning.

Brown, K. (2017). The arts and dropout prevention: The power of art to engage [White paper]. Clemson SC: National Dropout Prevention Center/Network. Retrieved June, 4, 2020 from http://dropoutprevention.org/wp-content/uploads/2017/10/arts-and-dropout-prevention-2017-10.pdf

Buseri, J. C. (2010, n.d.). Teaching practice: An imperative in teacher education [Paper Presentation]. Niger Delta University, Yenagoa, Bayelsa State, Nigeria.

Florence, O. O. (2015). National capacity building strategy in learning and teaching imperative for sustainable development of Nigeria educational system. Journal of Emerging Trends in Educational Research and Policy Studies, 6, 278-285.

Goodreads. (n.d.). https://www.goodreads.com/quotes/46630-donot-train-a-child-to-learn-by-force-or

Hurd, P. D. (1962). The education of secondary school biology teachers. The American Biology Teacher, 24, 327-331.

Jepsen, C. (2015). Class size: Does it matter for student achievement? IZA World Labor, 190.

Lakatos, A., and Borsos, A. (2011). Effective teaching methods for knowledge transfer improvement. Proceedings of Management, Knowledge and Learning International Conference, 455-464. http://www.issbs.si/press/ISBN/978-96192486-3-8/papers/ML11-50.pdf 
Lawali, M., Sadi, R. M., Abbas, B., and Kangiwa, R. M. (2015). Influx of unqualified teachers in teaching biology in secondary schools in sokoto [Bachelors thesis, Usmanu Danfodiyo University]. UDUS Open Educational Resources. http://oer.udusok.edu.ng:8080/xmlui/bitstream/ handle/123456789/468/MAIN\%20PROJECT.pdf?sequence $=1 \&$ isAllowed $=\mathrm{y}$

Mukuni, W. C. (2013). Job satisfaction of science teachers in public secondary schools in murang'a east district, murang'a county [Masters Thesis, Kenyatta University]. Semantic Scholar. https://pdfs.semanticscholar.org/295a/b7818ed9260605e83ece2973887009a993f4.pdf

National Academies of Sciences. (2016). Science Teachers' Learning Needs (Wilson, S., Schweingruber, H., and Nielsen, N., Eds.). The National Academies Press. Nakkazi, E. (2014, September 19). Universities must focus on science, not 'useless' arts. University World News. https://www.universityworldnews.com/post.php?story=20140918151012537.

Ngoboka, P., and Schultz, B. (2002). The effects of class size on student academic performance in a principles of microeconomics course. Proceedings of the Midwest Business Economics Association, 198-207). https://www.usi.edu/ media/3655163/Effects-of-Class-Size.pdf

Nwafor, N. E., Uchendu, E. E., and Akani, C. O. (2015). Need For adequate funding in the administration of secondary education in Nigeria. Global Journal of Educational Research, 14(2), 119-124.

O'Sullivan, M. C. (2002). Teacher development effective follow-up strategies for professional development for primary teachers in Namibia. Teacher Development, 6, 181-203.

Odia, L. O., and Omofonmwan, S. I. (2007). Educational system in Nigeria problems and prospects. Journal of Social Sciences, $14,86-85$.

OECD. (2009). Creating Effective Teaching and Learning Environments: First Results from TALIS. http://www.oecd.org/ education/school/43023606.pdf

Ofojebe, W., and Ezugoh, C. (2010). Teachers' motivation and its influence on quality assurance in the Nigerian educational system. African Research Review, 4, 398-417.

Olorundare, A. S., (2011). Correlates of poor academic performance of secondary students in the sciences in Nigeria [Paper Presentation]. Virginia State University, Petersburg, Virginia, USA.

Olmos-Gómez, C. M., Estrada-Vidal, L. I., Ruiz-Garzón, F., López-Cordero, R., and Mohamed-Mohand, L. (2019). Making future teachers more aware of issues related to sustainability: An assessment of best practices. Sustainability, 11, 7222 .

Omorogbe, E., and Ewansiha, J. C. (2013). The challenge of effective science teaching in Nigerian secondary schools. Academic Journal of Interdisciplinary Studies, 2(7), 181-188.
Oyeronke, A., and Fagbohun, M. (2013). An assessment of computer and ICT skills among secondary school teachers in Ota Ogun State. Library Philosophy and Practice.

Udu, D. A. (2018). Innovative practices in science education: A panacea for improving secondary school students' academic achievement in science subjects in Nigeria. Global Journal of Educational Research, 17, 23.

United Nation. (2013, June 10). Despite slight drop, number of children missing out on school remains high. https://news. un.org/en/story/2013/06/441872-despite-slight-drop-number-children-missing-out-school-remains-high-un-agency

Van Doorn, J. R., and Van Doorn, J. D. (2014). The quest for knowledge transfer efficacy: blended teaching, online and in-class, with consideration of learning typologies for non-traditional and traditional students. Frontiers in Psychology, 5, 324 .

Woodhouse, K. (2015, June 4). Colleges of arts and sciences struggle with deficits as enrollment declines. https://www.insidehighered.com/news/2015/06/04/colleges-arts-and-sciences-struggle-deficits-enrollment-declines

Zulkifli, O. (2014). The need for in-service training for teachers and it's effectiveness in school. International Journal for Innovation Education and Research, 2:1-9. 